\title{
Computed tomography findings in a cohort of 169 dogs with elbow dysplasia - a retrospective study
}

\author{
Mateusz Hebel ${ }^{1 \dagger}$, Wojciech K. Panek ${ }^{2}$, Jakub J. Ruszkowski ${ }^{3,4^{*}+}$ D, Maria Nabzdyk ${ }^{3}$, Dariusz Niedzielski ${ }^{5}$,
} Katarzyna C. Pituch ${ }^{6}$, Aaron M. Jackson ${ }^{7}$, Maciej Kiełbowicz ${ }^{1}$ and Małgorzata Pomorska-Mól ${ }^{8}$

\begin{abstract}
Background: Canine elbow dysplasia (CED) is a complex developmental skeletal disorder associated with a number of pathological conditions within the cubital joint. Because CED is a heritable disease, it is important to identify and remove the affected animals from breeding. The first objective of this study was to describe the prevalence of medial coronoid process disease (MCPD) without (MCD) or with (FMCP) fragmented medial coronoid process, osteochondrosis (OC) and/or osteochondritis dissecans (OCD), ununited anconeal process (UAP), radio-ulnar incongruence (INC R-U) and humero-ulnar incongruence (INC H-U) in dogs with the use of CT imaging. The second aim was to determine the influence of demographics on the prevalence of investigated pathologies in dogs with clinical evidence of elbow dysplasia.
\end{abstract}

Results: In this retrospective study, CT data records of 169 dogs of different breeds presented to the small animal veterinary clinic from 2012 to 2018 were included. 69.23\% of dogs diagnosed with CED were young ( $\leq 2$ years old). The mean age of dogs presented with INC R-U was $1.68 \pm 1.82$ years, while in dogs without INC R-U the mean age was $2.64 \pm 2.59$ years. The mean age of dogs with INC H-U was $1.94 \pm 2.06$ years, while without INC H-U $3.29 \pm 2.09$ years. Labrador Retrievers, German Shepherd and Bernese Mountain dogs were most frequently presented with CED-associated lameness. In 122 dogs OA of varying severity was found.

Conclusion: INC H-U, FMCP and MCD were among the most frequently found components of CED found in the present study. OCD and UAP were the least frequently diagnosed. Dogs presented with INC R-U and INC H-U were significantly younger than dogs without these CED components. Boxers, Dog de Bordeaux, American Staffordshire terriers and mixed-breed dogs were diagnosed later in life than the other breeds. OA of varying severity was found in $72.18 \%$ of dogs. Males accounted for more than $75 \%$ of the study population.

Keywords: Canine elbow dysplasia, CED, CT, Imaging, Dogs

\footnotetext{
* Correspondence: ruszkowskij@gmail.com

${ }^{\dagger}$ Mateusz Hebel and Jakub J. Ruszkowski contributed equally to this work.

${ }^{3}$ Department of Animal Anatomy, Poznan University of Life Sciences, ul.

Wojska Polskiego 71C, 60-625 Poznań, Poland

${ }^{4}$ University Centre for Veterinary Medicine, Szydłowska 43, 60-656 Poznan,

Poland

Full list of author information is available at the end of the article
}

(c) The Author(s). 2021 Open Access This article is licensed under a Creative Commons Attribution 4.0 International License, which permits use, sharing, adaptation, distribution and reproduction in any medium or format, as long as you give appropriate credit to the original author(s) and the source, provide a link to the Creative Commons licence, and indicate if changes were made. The images or other third party material in this article are included in the article's Creative Commons licence, unless indicated otherwise in a credit line to the material. If material is not included in the article's Creative Commons licence and your intended use is not permitted by statutory regulation or exceeds the permitted use, you will need to obtain permission directly from the copyright holder. To view a copy of this licence, visit http://creativecommons.org/licenses/by/4.0/ The Creative Commons Public Domain Dedication waiver (http://creativecommons.org/publicdomain/zero/1.0/) applies to the data made available in this article, unless otherwise stated in a credit line to the data. 


\section{Background}

Canine elbow dysplasia (CED) is a prevalent health issue that affects many breeds, particularly medium to large sized dogs, however it is also reported in smaller chondrodystrophic breeds like Dachshund and French bulldog [1-3]. Elbow dysplasia is relatively common in dogs with the reported prevalence in animals presented for breed screening up to $70 \%$ in Bernese mountain dogs [4], 17.0-29.6\% in Labradors [5-7], 26\% in Newfoundlands [8]. Several research reports confirmed that certain breeds tend to be affected by a particular entity more frequently than others $[2,9]$.

CED is a complex developmental skeletal disorder associated with a number of pathological conditions within the cubital joint $[1,10,11]$. Complex primary conditions associated with elbow dysplasia included medial coronoid process disease (MCPD), osteochondrosis (OC) and/or osteochondritis dissecans (OCD), ununited anconeal process (UAP), and joint incongruency (INC) and may be identified separately as a singular cause of elbow dysplasia or occur as a combination of lesions presented simultaneously [1, 12]. Due to the changes observed in the CT image, the MCPD was divided into two groups: without fragmented medial coronoid process (MCD) and with fragmented medial coronoid process (FMCP).

Elbow dysplasia can cause lameness, and arthroscopic treatments do not palliate pain in all affected dogs [13, $14]$. Because CED is a heritable disease, it is very important to identify and remove the affected animals from breeding to decrease the incidence of CED in dogs. Although some lesions, including UAP and OCD of the humerus, are quite often successfully identified on plain radiographs, appropriate diagnosis of the MCD or FMCP may be less straight-forward due to superimposition of medial epicondyle and muscle tissue [15]. Computed tomographic imaging is recognized as a high-sensitivity tool that allows for a detailed visualization of the skeletal components of the joints [12, 16-18]. Moreover, computer tomography (CT) enables not only detection but also monitoring of progression in elbow dysplasia [17]. Recently, the use of CT has become increasingly widespread in veterinary medicine. Current data indicate that some components of CED (i.e. MCPD) might be detected as early as 14 weeks of age $[19,20]$. Data from previous report indicated that CT should be used when investigating elbow joint diseases in young dogs [19]. However, the number of CT - based studies assessing prevalence of different CED lesions in dogs, including dogs of different breeds is limited [21, 22]. Evaluation of correlations between certain components of CED and specific demographic and/or phenotypic features may allow for more appropriate research in the future and ultimately lead to the identification of new risk factors [23].
The first objective of this study was to evaluate the prevalence of MCPD (MCD and FMCP), OC and/or OCD, UAP, radio-ulnar incongruence (INC R-U) and humero-ulnar incongruence (INC $\mathrm{H}-\mathrm{U}$ ) in dogs with the use of CT imaging. The second aim was to determine the influence of demographics (breed, age, sex) on the prevalence of investigated pathologies in dogs with clinical evidence of elbow dysplasia.

\section{Methods \\ Animals}

The study was conducted on CT data records of 169 dogs of different breeds admitted to the small animal veterinary clinic (Klinika Psa i Kota, Wrocław, Poland) from February 2012 to November 2018. Dogs were referred for diagnostic CT imaging due to bilateral or unilateral elbow lameness detected on the basis of a clinical examination conducted by an orthopedic specialist. Only dogs diagnosed with CED were included in the study. Inclusion criteria for study population were: 1) presenting complaint of elbow lameness and CED components in CT image 2) complete information on demographic feature (breed, age, body weight) 3) clinical and orthopedic examination; 4) diagnostic quality CT scans. The exclusion criteria were non-CED associated elbow lameness and incomplete medical records. Data collected from the medical records included: clinical signs (bilateral or unilateral elbow lameness), age and body weight at admission, diagnostic procedures performed.

\section{Study design}

For each dog the following data were retrospectively gathered: breed, age (at the time of first diagnosis), sex and weight. 169 dogs with CED were divided into three different weight categories: medium $(15-25 \mathrm{~kg}, n=16)$, large $(26-44 \mathrm{~kg}, n=122)$ and extra-large $(\geq 45 \mathrm{~kg}, n=31)$.

All dogs underwent physical and orthopedic examinations followed by a complete blood count and serum biochemistry tests. All study participants were able to walk without assistance. The assessment of mobility function and presence of lameness was performed by one orthopedic specialist veterinary surgeon. CT scans were assessed by two veterinary radiology specialists.

Owners obtained a written description of the study and they provided written informed consent for the inclusion of their dogs in the study.

\section{$\mathrm{CT}$ imaging and analysis}

The prevalence of UAP, OCD, MCD, FMCP, INC R-U and INC $\mathrm{H}-\mathrm{U}$ in dogs with CED was estimated on the basis of the results of CT imaging. MCD and FMCP lesions were analyzed separately. The degree of OA was assessed based on International Elbow Work Group 


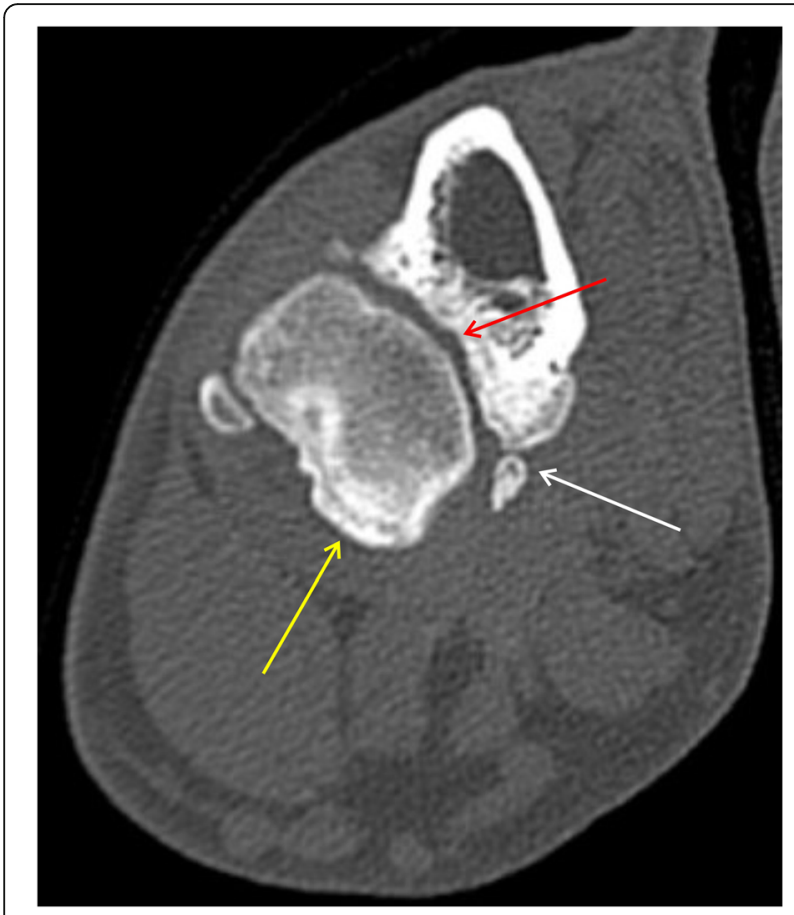

Fig. 1 Sagittal MPR image was established via alignment of external borders of humerus and ulna on a dorsal plane (red lines)

(IEWG) guidelines [24]. A total of 338 elbow joints were screened with CT-imaging.

CT images were obtained with a 2-slice helical scanner (Twin, Elscint, Israel) or 16-slice helical scanner (Somatom, Siemens. Germany) using $120 \mathrm{kVp}$ or $110 \mathrm{kVp}$, $100 \mathrm{~mA}$, pitch 0.8 and reconstructed slices were $0.6 \mathrm{~mm}$ with an overlapping slice index of $0.5 \mathrm{~mm}$. Dogs were sedated with intramuscular injection (i.m) of medetomidine in a dose of 5-20 $\mu \mathrm{g}$ (micrograms) $/ \mathrm{kg}$ and butorphanol $(0.1-0.4 \mathrm{mg} / \mathrm{kg})$. Induction was obtained with propofol in a dose of $3.2 \mathrm{mg} / \mathrm{kg}$ of body weight administered intravenously followed by endotracheal tube placement. Isoflurane and 100\% oxygen were used for anesthesia maintenance. During the CT scan dogs were placed in sternal recumbency with both thoracic limbs extended cranially and head was shifted out of the gantry to avoid potential artefacts. DICOM files of each scan were analyzed by an experienced veterinary radiologist using 3D MPR tool in OsiriX (64-bit software, Pixmeo, Geneva, Switzerland) to evaluate the scans in sagittal and dorsal planes.

The level of OA in each elbow joint was scored according to IEWG [24] and the following scores were assigned: 0 - normal elbow joint (no evidence of incongruity, sclerosis or arthrosis); 1- mild arthrosis or suspect primary lesion (presence of osteophytes $<2 \mathrm{~mm}$, sclerosis of the base of the coronoid processes and subtrochlear ulnar region trabecular pattern still visible); 2- moderate arthrosis (presence of osteophytes 2-5 mm, obvious sclerosis (no trabecular pattern) of the base of the coronoid processes, step of 3-5 mm between radius and ulna (incongruity), indirect signs for other primary lesion (UAP, FMCP/coronoid disease, OCD); 3- severe arthrosis or evident primary lesion (presence of osteophytes $>5 \mathrm{~mm}$, step of $>5 \mathrm{~mm}$ between radius and ulna (obvious incongruity), obvious presence of a primary lesion (UAP, FMCP, OCD) [8].

Assessment of joint incongruency was done using multiplanar reconstructions (MPR) in the mid-coronoid region in an oblique plane, according to scheme presented previously $[25,26]$. Sagittal MPR image was established via alignment of external borders of humerus and ulna on a dorsal plane (red lines) (Fig. 1). The reformatted sagittal plane was used to measure incongruence at the base of the coronoid and reformatted dorsal planes were used to assess incongruence at the mid and cranial coronoid regions. Sagittal and dorsal plane MPR reconstructions ( $\mathrm{A}$ and $\mathrm{B}$ ) were used for the evaluation of radio-ulnar incongruence (Fig. 2). INC-RU was defined as the distance between the sub-chondral bone surfaces of the radioulnar articulation at the caudal ulnar

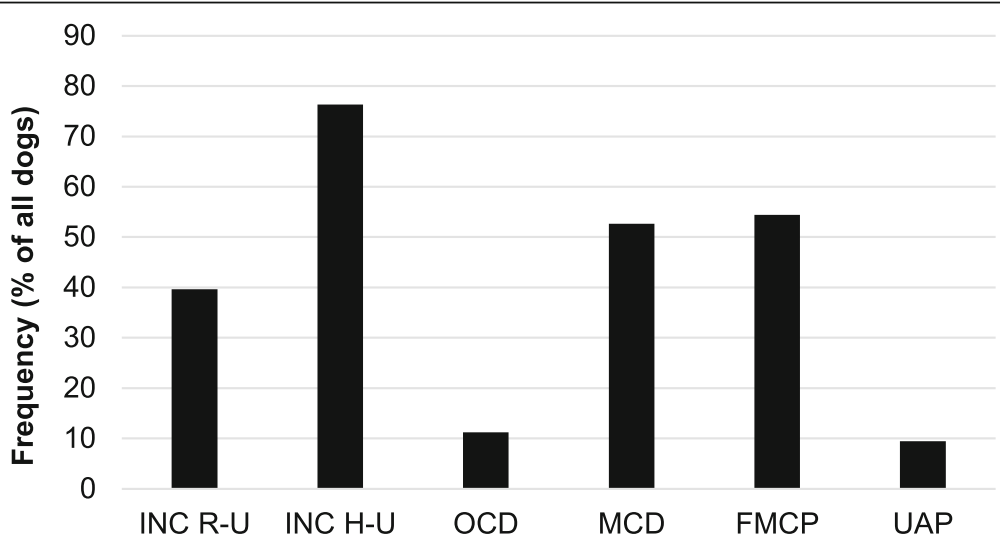

Fig. 2 Sagittal and dorsal plane MPR reconstructions (A and B) were used for the evaluation of radio-ulnar incongruence 


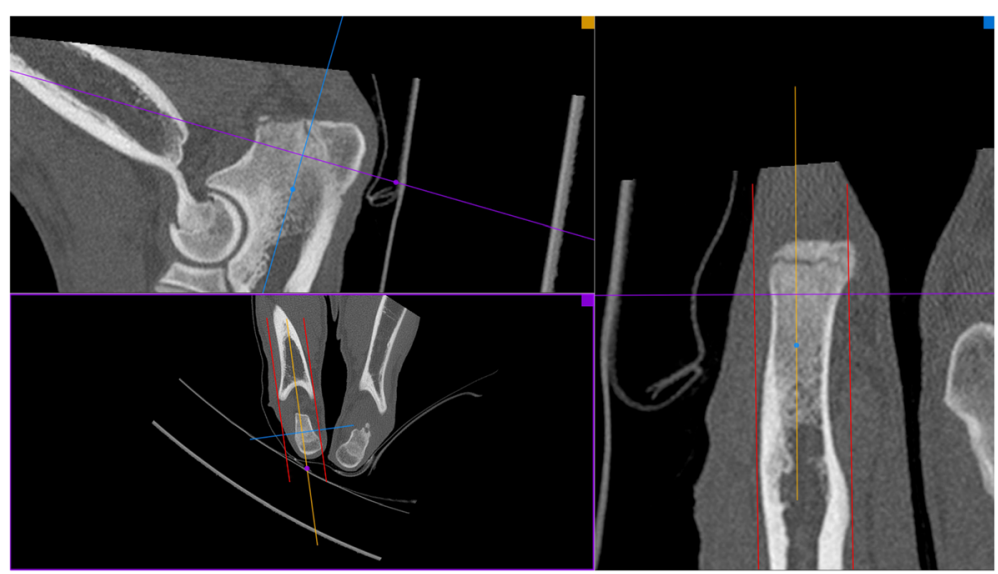

Fig. 3 Sagittal CT slice (MPR reconstruction), showing three ulnar measurement loci (distances measured between green lines) for the assessment of humero-ulnar incongruence (INC H-U). Same slice has been used to evaluate ununited anconeal process (UAP), (borders marked with red dotted line) $[25,29]$

incisure, mid-body, and cranial apex. Joints with a reduction of the radial articular surface in relation to the ulna by $1.6 \mathrm{~mm}$ and more were considered as affected with INC-RU [25, 27].

Humero-ulnar incongruency was subjectively evaluated based on the width of the joint space at the greatest caudal convexity of the trochlear notch of the ulna [28]. The sagittal CT slice (MPR reconstruction), showing three ulnar measurement loci (distances measured between green lines) for the assessment of INC $\mathrm{H}-\mathrm{U}$ is presented in Fig. 3. Same slice has been used to evaluate UAP, (borders marked with red dotted line).

Transverse plane MPR reconstruction (C) at the level of medial coronoid process of the ulna (borders marked with red line) was used for the assessment of MCPD pathology (Fig. 4).
In the present study, focal marked sclerosis causing thickening of the subchondral plate was diagnosed as "kissing lesion”, while a radiolucent subchondral defect on the distal medial trochlea was diagnosed as OCD.

The typical changes observed in the present study are presented in Figs. 5, 6, 7, 8, 9, 10, 11.

\section{Statistical analysis}

The obtained data were subjected to the W. Shapiro-Wilk test for normality and the Levene's test for equality of variances. Differences between means (the mean age of CED affected dogs in particular weight category groups) were tested for statistical significance by a nonparametric Kruskal-Wallis test with post hoc multiple comparisons for comparison of all pairs. For analysis of relationship between the occurrence of various CED component and demographic features (age and body weight)

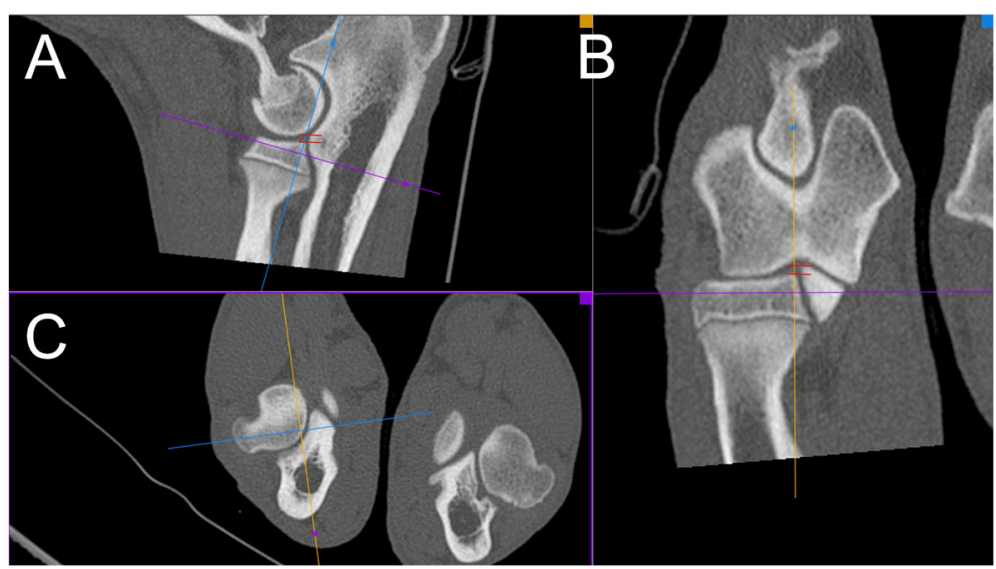

Fig. 4 Transverse plane MPR reconstruction (C) at the level of medial coronoid process of the ulna (borders marked with red line) was used for the assessment of MCP pathology [29] 


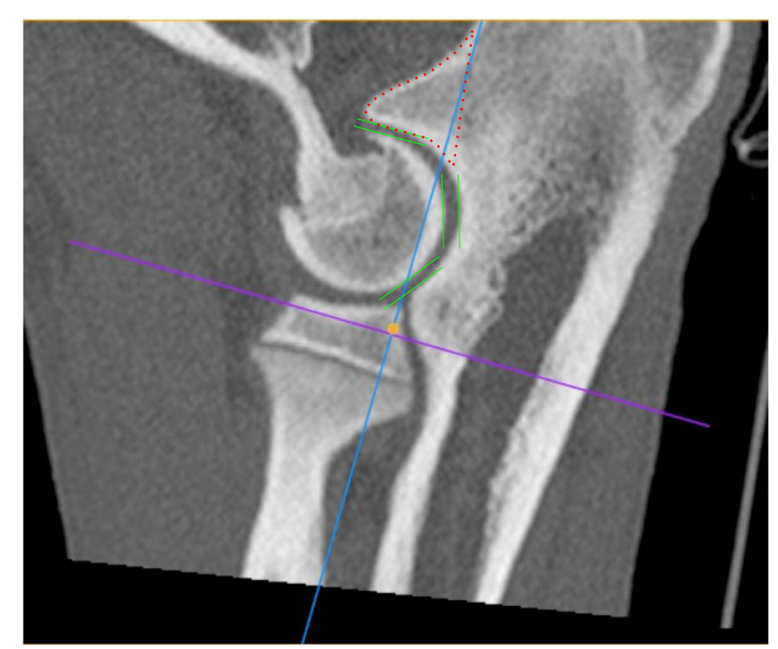

Fig. 5 MPR reformatted images in sagittal plane. Yellow arrow shows humero-ulnar incongruity. Green arrow shows subchondral bone sclerosis in trochlear notch of ulnar bone. Red arrow shows osteophytes on the dorsal border of the anconeal process $[25,29]$

of the tested dogs the U Mann-Whitney test were used. Differences were considered as significant with $\alpha<0.05$. All calculations were performed with Statistica 13.3 (Tibco, USA).

\section{Results}

\section{Dogs characteristics}

169 dogs of various breeds met the inclusion criteria (41 females and 128 males). Thirty-one pure breeds were represented. In addition, two mixed-breed dogs were included. The dogs' ages ranged from 5 months to 10.0 years (median 1 year) and body weights from 15.0 to $70.0 \mathrm{~kg}$ (median $36.0 \mathrm{~kg}$ ). Detailed characteristics and demographic features of each dog are presented in Table 1. Sixteen dogs were classified to medium weight category, 122 to large weight category, and 31 to extralarge weight category. Detailed characteristics of

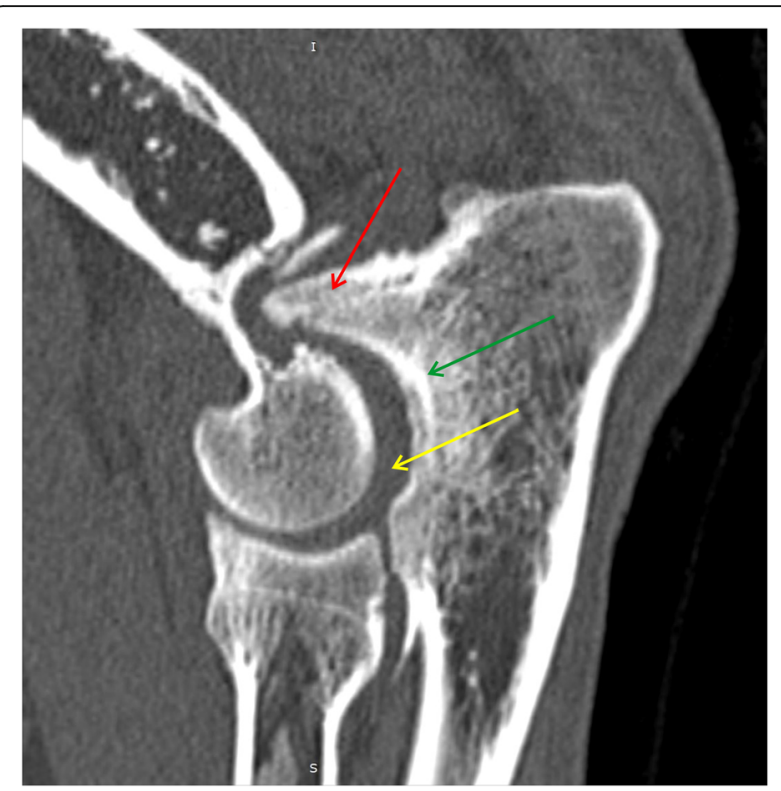

Fig. 7 MPR reformatted images in sagittal plane. Space between yellow line shows radioulnar incongruity. Red arrow shows humeroulnar incongruity. Green arrow shows osteophytes on the dorsal border of the anconeal process $[25,29]$

demographic features in three weight categories are presented in Tables 2 and 3.

The significant differences have been found between age of dogs affected and not affected with INC R-U and INC H-U ( $p=0.02$ and $p=0.01$, respectively). The mean age of dogs with INC R-U was $1.68 \pm 1.82$ years (with a median of 0.83 ), whereas in dogs without this component of CED the mean age was $2.64 \pm 2.59$ years (with a median of 1.5 ). Similar results were obtained with INC H-U. The mean age of dogs with INC H-U was $1.94 \pm 2.06$ years (with a median age of 1 year), whereas in dogs affected by CED but without INC H$\mathrm{U}$, the mean age was $3.29 \pm 2.09$ years (with a median age of 2 years). For the other components of CED (OCD, MCD,

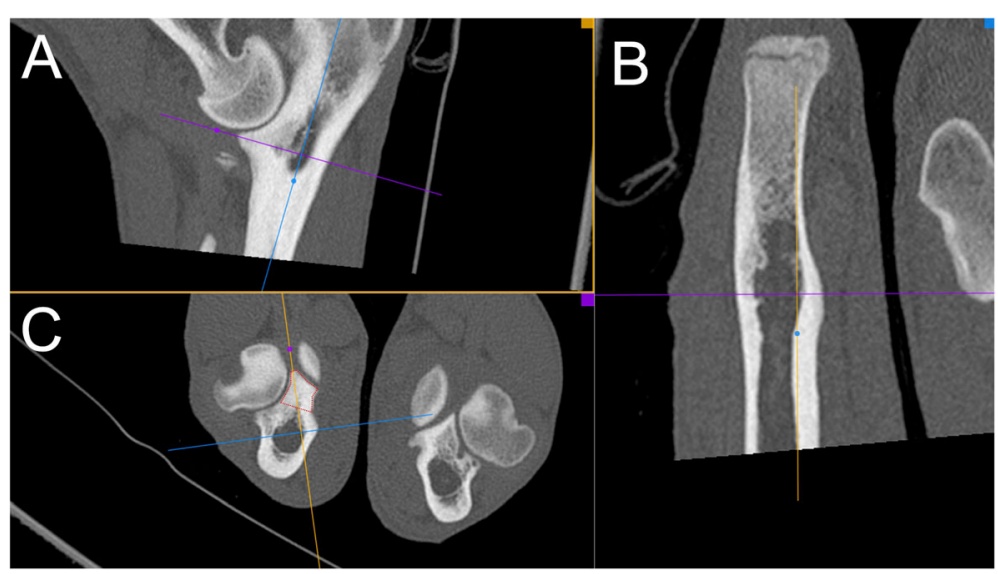

Fig. 6 MPR reformatted images in dorsal plane. Space between yellow line shows radioulnar incongruity [25, 29] 


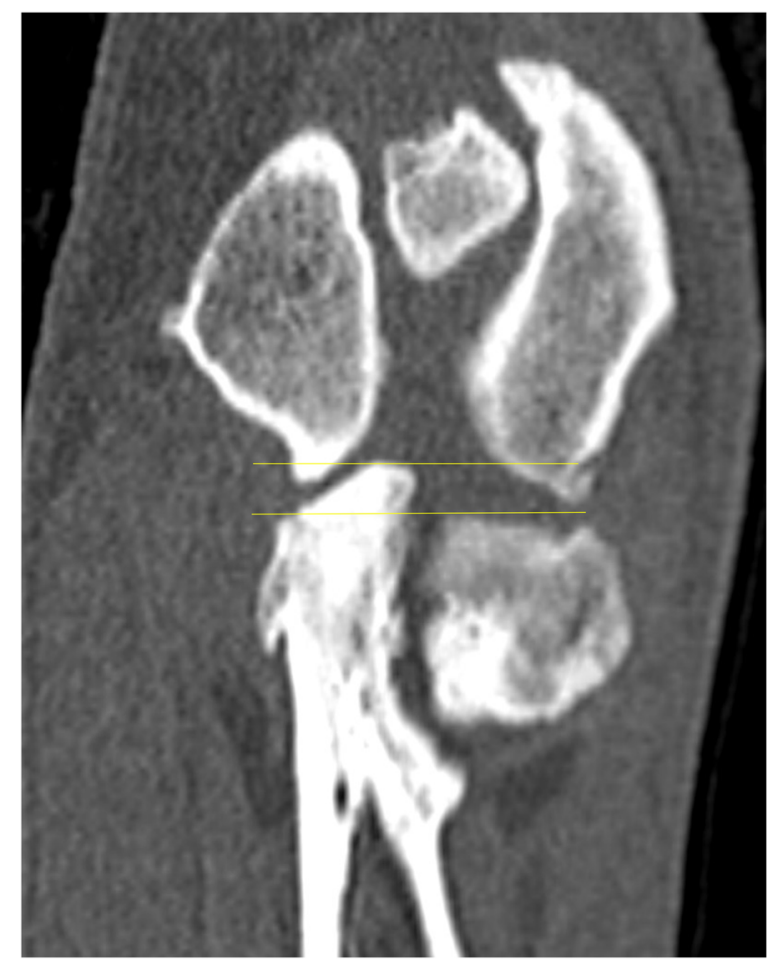

Fig. 8 MPR reformatted images in sagittal plane. Red arrow shows humero-ulnar incongruity and subchondral bone sclerosis in trochlear notch of ulnar bone. Green arrow shows ununited anconeal process (UAP) $[25,29]$
FMCP and UAP), no age-related differences were found between dogs with and without the pathology studied $(p \geq$ 0.05).

A more detailed analysis showed that in the youngest dogs (up to 6 months), INC H-U and/or FMCP were the most common pathologies. In dogs aged between 6 months and 2 years, INC $\mathrm{H}-\mathrm{U}$ and/or FMCP were also most frequently found. In older dogs, aged between 3 and 6 years, the INC H-U, MCD and/or FMPC were the most common. In the oldest dogs, aged over 6 years, INC H-U and MCD were the most often observed. Details of the occurrence of the investigated pathologies in dogs of different ages are shown in Table 4.

No significant differences were found for the mean body weight of dogs with or without each investigated pathology (INC R-U, INC H-U, OCD, MCD, FMCP and UAP) $(p \geq 0.05)$.

In dogs from medium weight category the most common pathologies were INC $\mathrm{H}-\mathrm{U}$ (9/16) and FMCP (8/ 16), while UAP was observed only in 2 out of 16 dogs. In dogs from large weight category INC $\mathrm{H}-\mathrm{U}$ was found in 90/122, while FMCP and MCD were found in 66 and 63 dogs out of 122, respectively. The OCD and UAP were found the least frequently (in 11 and 13 dogs,

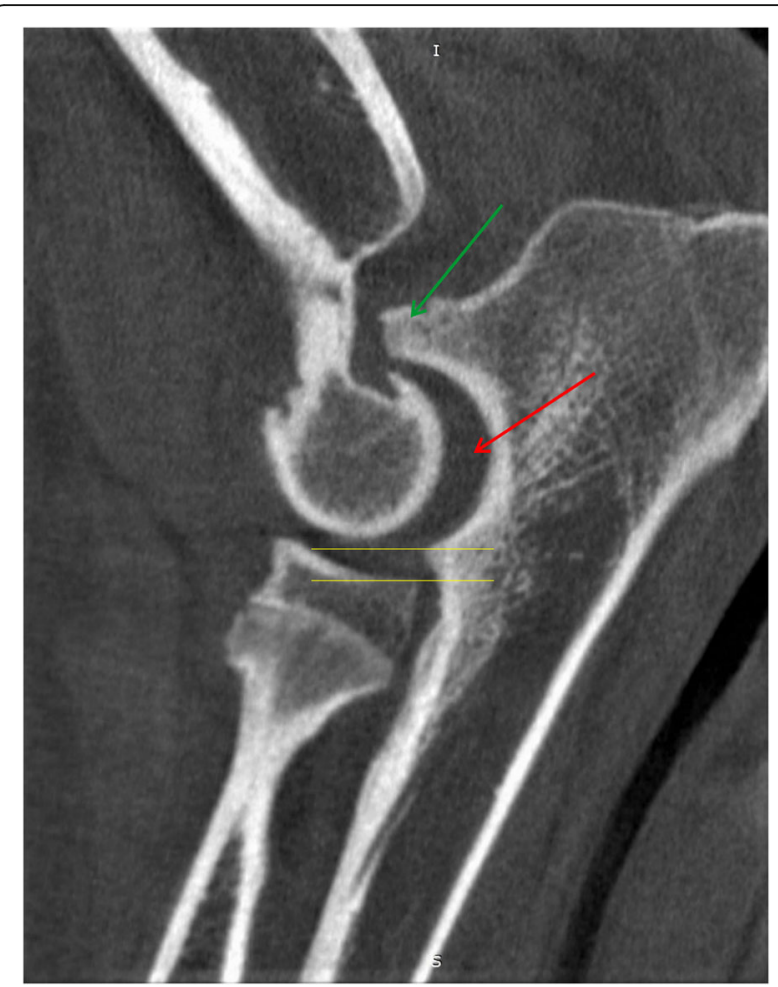

Fig. 9 MPR reformatted images in sagittal plane. Red arrow shows defect of the subchondral bone surface of the humeral trochlea, with local subchondral bone sclerosis - OCD. Yellow arrow shows fragmented medial coronoid process (FMCP)

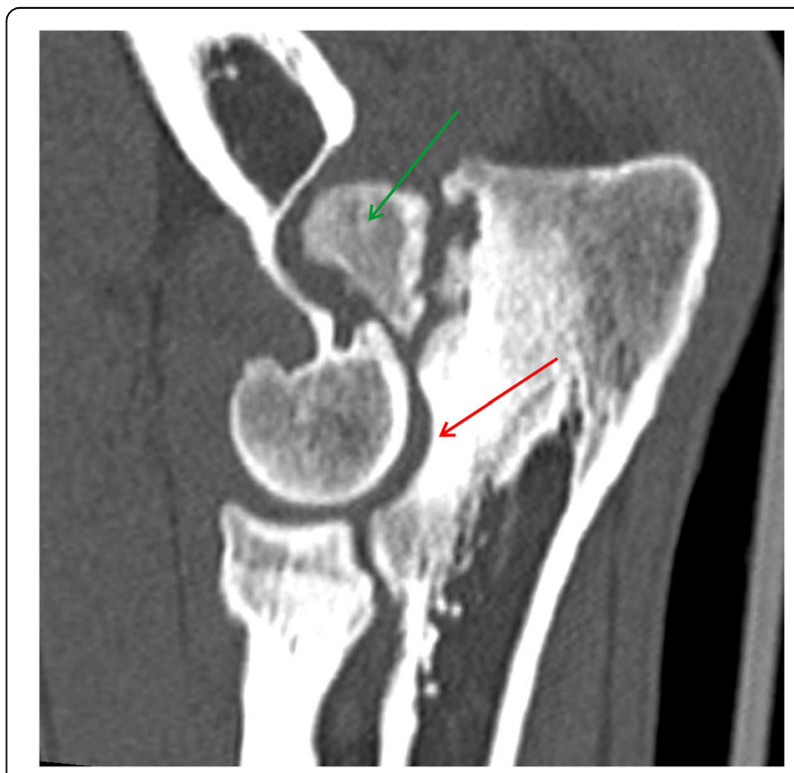

Fig. 10 Axial scan on the level of the medial coronoid process of the ulnar bone. White arrow shows inhomogeneous medial coronoid process with small osteophyte on his apex, what suggests medial coronoid process disease 


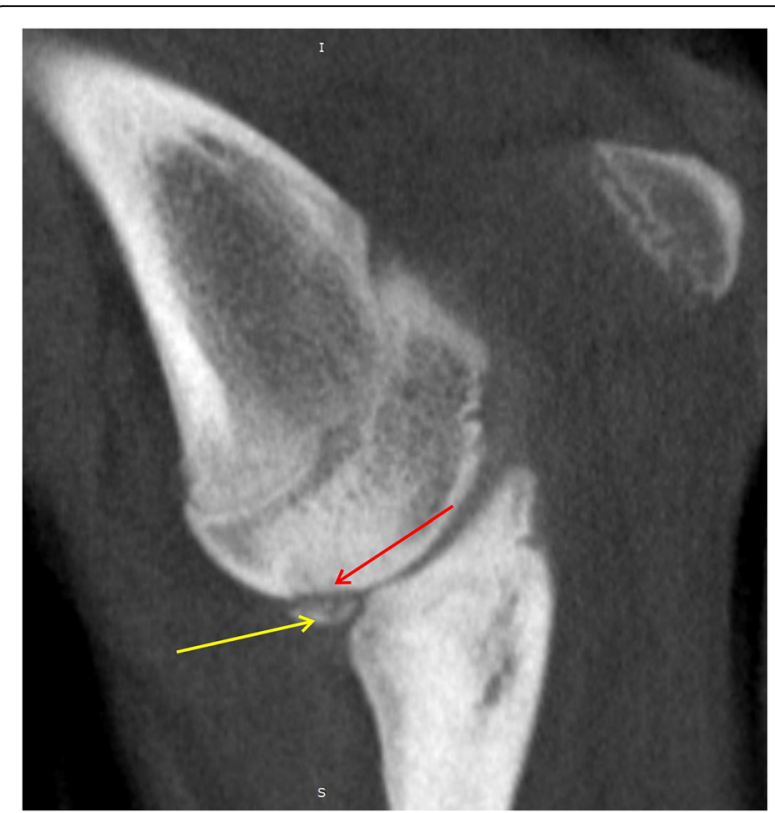

Fig. 11 Axial scan on the level of the medial coronoid process of the ulnar bone. White arrow shows fragmented medial coronoid process with small osteophyte on border. Red arrow shows irregular surface of the subchondral bone of the radial notch of ulna. Yellow arrow shows osteophytes on the cranial border of the radial head

respectively). In the extra-large category the most common finding were INC H-U (26/32) and MCD (19/32), while UAP was found in only 4 out of 32 dogs. The percentage of dogs with various components of CED in particular weight category is presented in Table 5 .

Labrador Retrievers (43\%), German Shepherd dogs (GSD) (40\%) and Bernese Mountain dogs (15\%) were most frequently presented with CED-associated lameness. In addition, patients belonging to these breeds represented the majority of the subjects within the cohort of large-size dogs, with weights ranging between 29.0 and $50.0 \mathrm{~kg}$ for GSD, 20.5 and $47.0 \mathrm{~kg}$ for Labrador Retrievers, and 33.0 and $50.5 \mathrm{~kg}$ for Bernese Mountain dogs.

In 47 dogs no signs of OA were observed on CT, while in the other 122 animals OA of varying severity was found. Within dogs with OA, 57/122 (46.72\%) were assigned a grade $1 ; 27 / 122(22.13 \%)$ were assigned a grade $2 ; 38 / 122(31.14 \%)$ were assigned a grade 3 . It is worth to mention that dogs with a different degree of $\mathrm{OA}$ in each joint were classified to the group corresponding to the higher degree of OA. $11.6 \%$ of dogs were diagnosed with unilateral CED and $88.4 \%$ suffered from bilateral CED.

The percentage distribution of CED lesions across the population of dogs included in the study is shown in Fig. 12.
One hundred and seventeen dogs out of 169 (69.23\%) of dogs diagnosed with CED in our study were 2 years old or less. Several breeds, including Boxers, Dog de Bordeaux, American Staffordshire terriers and Mixed-breed dogs, were presented later in the course of their lifespan. Median age in these groups was: 6 years for boxers (mean $5.0 \pm 3.0$ years); 3.0 years for mixed-breed dogs (mean $4.5 \pm 2.59$ years); 4.75 years for American Staffordshire terriers (mean $5.16 \pm 3.70$ years) and 3.5 years for Dog de Bordeaux group (mean $3.16 \pm 2.45$ years).

The prevalence of CED components within breeds (along with the absolute number of dogs affected) and the occurrence of these pathologies in single-digit breeds are shown in Tables 6 and 7, respectively.

\section{Discussion}

Computed tomography imaging performed in a large cohort of CED - affected dogs allowed for assessment of prevalence of different CED components for each breed and across the whole population of dogs included in the present study. In accordance with previous findings, in the present study the elbow dysplasia was more common in males than in females [21].. It is hypothesized that sex distribution is associated with dominant inheritance within male linage [30]. The demographic data demonstrate inclusion of dogs of typical breeds (mostly large breeds) affected by CED, with wide range in age and severity of pathology. However, dogs presented with INC R-U and INC H-U were significantly younger than dogs without these CED components. In our study, similarly to data presented previously [31], lameness associated with CED was most common in Labrador Retriever and GSDs. In addition to CED, approximately $57 \%$ of dogs included in our study were diagnosed with concurrent $\mathrm{OA}$ of various degrees. Previous findings indicated that OA can develop as a primary lesion, although the presence of degenerative changes is often directly related to the development and progression of CED [32].

In the one-year prevalence study conducted by O'Neill et al. [26] the most common breeds among the incident elbow joint disease were Labrador Retriever $(n=189$, $30.68 \%)$, GSD ( $n=43,6.98 \%)$, Staffordshire Bull Terrier $(n=32,5.19 \%)$ and Rottweiler $(n=23,3.73 \%)$, along with crossbred dogs ( $n=100,16.23 \%)$.

Our study showed that $11.6 \%$ of dogs were diagnosed with unilateral CED and $88.4 \%$ suffered from bilateral CED. The INC H-U was the most common finding, and approximately $40 \%$ of dogs diagnosed with INC $\mathrm{H}-\mathrm{U}$ were also affected by MCD. Similar results were observed previously in Labrador Retrievers and Golden Retrievers [15].

Radio-ulnar incongruence was detected in $39.6 \%$ of dogs included in the present study, and approximately $50 \%$ of these dogs were also affected by FMCP. Previous 
Table 1 Characteristics of dogs included in the study. Data were collected from 169 dogs with canine elbow dysplasia

\begin{tabular}{|c|c|c|c|c|}
\hline Breed & Number of included dogs & Median age years (range) & Sex (number) males/females & $\begin{array}{l}\text { Median weight } \\
\text { kg (range) }\end{array}$ \\
\hline Labrador Retriever & 43 & $1.5(0.4-10)$ & $36 / 7$ & $35.16(25-47)$ \\
\hline German Shepherd Dog & 40 & $0.91(0.4-9.0)$ & $29 / 11$ & $36.74(29-50)$ \\
\hline Bernese Mountain dog & 15 & $1(0.5-6.5)$ & $12 / 3$ & $42.4(33-55)$ \\
\hline Chow Chow & 6 & $1.04(0.4-3.0)$ & $4 / 2$ & $22.5(15-28)$ \\
\hline Boxer & 5 & $6(2.0-9.0)$ & $2 / 3$ & $33(19-40)$ \\
\hline Golden Retriever & 5 & $0.58(0.4-3.5)$ & $3 / 2$ & $28.6(19-36)$ \\
\hline Dog de Bordeaux & 5 & $3.5(0.5-6.0)$ & $3 / 2$ & $52.4(27-70)$ \\
\hline Cane Corso & 5 & $0.83(0.4-3.0)$ & $4 / 1$ & $39.8(26-50)$ \\
\hline White Swiss Shepherd & 4 & $0.7(0.5-1.0)$ & $4 / 0$ & $31(28-33)$ \\
\hline Rottweiler & 4 & $1.4(0.5-6.0)$ & $3 / 1$ & $44(39-52)$ \\
\hline American Staffordshire Terrier & 3 & $4.75(1-10)$ & $3 / 0$ & $30.3(29-32)$ \\
\hline Polish Tatra Sheepdog & 3 & $0.66(0.58-3.0)$ & $2 / 1$ & $44.3(32-61)$ \\
\hline Bouvier des Flandres & 3 & $0.83(0.4-3.0)$ & $2 / 1$ & $37.3(35-41)$ \\
\hline English Bulldog & 3 & $0.83(0.8-3.0)$ & $3 / 0$ & $33.3(24-44)$ \\
\hline Mixed-breed & 2 & $3 \& 7.5$ & $2 / 0$ & $37 \& 35$ \\
\hline Newfoundland & 2 & $0.66 \& 1.0$ & $2 / 0$ & $61 \& 60$ \\
\hline Caucasian Shepherd & 2 & $0.4 \& 1.5$ & $2 / 0$ & $20 \& 50$ \\
\hline Eurasian Shepherd & 2 & $0.5 \& 2.0$ & $1 / 1$ & $47 \& 68$ \\
\hline Pitbull & 2 & $0.4 \& 0.5$ & $1 / 1$ & $20 \& 25$ \\
\hline Argentinian Mastiff & 2 & $1 \& 3.0$ & $2 / 0$ & $58 \& 59$ \\
\hline Border Collie & 1 & 1.5 & $1 / 0$ & 23 \\
\hline Bullmastiff & 1 & 0.66 & $1 / 0$ & 50 \\
\hline Australian Cattle dog & 1 & 2.0 & $0 / 1$ & 23 \\
\hline Beagle & 1 & 5.0 & $1 / 0$ & 23 \\
\hline St. Bernard & 1 & 0.5 & $1 / 0$ & 40 \\
\hline American Bully & 1 & 0.58 & $1 / 0$ & 26 \\
\hline Great Dane & 1 & 1.5 & $0 / 1$ & 36 \\
\hline Greater Swiss Mountain & 1 & 1.0 & $1 / 0$ & 51 \\
\hline Flat Coated Retriever & 1 & 1.0 & $1 / 0$ & 30 \\
\hline Spanish Mastiff & 1 & 0.75 & $0 / 1$ & 60 \\
\hline Shar-pei & 1 & 1.0 & $0 / 1$ & 25 \\
\hline Giant Schnauzer & 1 & 1.5 & $1 / 0$ & 42 \\
\hline Spanish Alano & 1 & 0.5 & $0 / 1$ & 52 \\
\hline
\end{tabular}

Table 2 Descriptive statistics of study population: body weight

(kg)

\begin{tabular}{lllllll}
\hline Weight & \multicolumn{6}{l}{ Body weight $(\mathbf{k g})$} \\
\cline { 2 - 7 } category & $\mathbf{n}$ & Mean & Median & Minimum & Maximum & SD \\
\hline Medium & 16 & 21.87 & 23.00 & 15.00 & 25.00 & 3.05 \\
Large & 122 & 35.24 & 35.00 & 26.00 & 44.00 & 4.90 \\
Extra-large & 31 & 52.80 & 50.00 & 45.00 & 70.00 & 6.74 \\
\hline
\end{tabular}

$n$ number of dogs; $S D$ standard deviation
Table 3 Descriptive statistics of study population: age (years)

\begin{tabular}{lllllll}
\hline $\begin{array}{l}\text { Weight } \\
\text { category }\end{array}$ & \multicolumn{6}{l}{ Age (years) } \\
\cline { 2 - 7 } $\mathbf{n}$ & Mean & Median & Minimum & Maximum & SD \\
\hline Medium & 16 & 1.14 & 0.58 & 0.41 & 6.00 & 1.40 \\
Large & 122 & 2.41 & 1.00 & 0.41 & 10.00 & 2.56 \\
Extra-large & 31 & 2.27 & 1.50 & 0.50 & 6.50 & 1.80 \\
\hline$n$ number of dogs; SD standard deviation & & &
\end{tabular}


Table 4 The frequency (\%) and absolute number of dogs affected with various components of CED depending on age category

\begin{tabular}{lcccccc}
\hline \multirow{2}{*}{$\begin{array}{l}\text { Age of dogs } \\
\text { (years) }\end{array}$} & \multicolumn{2}{l}{ Frequency (\%) of CED components } & & & \\
\cline { 2 - 7 }$<0.5$ & INC R-U & INC H-U & OCD & MCD & FMCP & UAP \\
\hline \multirow{2}{*}{$0.5-2$} & $(43.48)$ & 91.3 & 4.34 & 43.48 & 82.61 & 8.69 \\
& $10 / 23$ & $21 / 23$ & $1 / 23$ & $10 / 23$ & $19 / 23$ & $2 / 23$ \\
\hline \multirow{2}{*}{$3-6$} & 41.3 & 75.0 & 11.95 & 52.17 & 54.34 & 8.69 \\
& $38 / 92$ & $69 / 92$ & $11 / 92$ & $48 / 92$ & $50 / 92$ & $8 / 92$ \\
\hline \multirow{2}{*}{6} & 32.5 & 57.5 & 15.0 & 52.5 & 50.0 & 12.5 \\
& $13 / 40$ & $23 / 40$ & $6 / 40$ & $21 / 40$ & $20 / 40$ & $5 / 40$ \\
\hline
\end{tabular}

$n$ number of dogs; the most common finding in each age category is marked in green. CED canine elbow dysplasia; INC R-U radio-ulnar incongruence; INC H-U humero-ulnar incongruence; FMCP medial coronoid disease with fragmented medial coronoid process; $O C D$ osteochondrosis dissecans within the medial compartment of humeral condyle coronoid process; $M C D$ medial coronoid disease without fragmented medial coronoid process (pathological cartilage and or subchondral bone); UAP ununited anconeal process

study conducted by Eljack et al. (2013) showed, that up to $60 \%$ of dogs diagnosed with INC R-U were simultaneously affected by MCD, which complies with our findings [33]. Interestingly, $100 \%$ of the Chow Chow's included in the present study $(n=6)$ were simultaneously affected by INC H-U and FMCP. This may be associated with generally higher heritability values for this breed as has been shown previously [1]. Osteochondritis dissecans was detected in $11.24 \%$ of dogs and was always accompanied by other CED lesions. In our study, the least common lesion found was UAP, which was present in $9.46 \%$ of dogs. Similar low prevalence of OCD and UAP was reported previously [9]. Simultaneous occurrence of FCMP and UAP was previously reported to be not common findings [34-36]. In the present study similar results were obtained. The simultaneous presence of FMCP and UAP was observed only in 3 dogs (GSD,
Bernese Mountain Dog, Cane corso). Interestingly, in the present study several breeds with CED - associated lameness were older at first diagnosis (Boxers, Dog de Bordeaux, American Staffordshire Terriers and crossbreed dogs). However, we cannot present data on the time of first appearance of clinical signs in the tested dogs, which is one of the limitations of our study and should be taken into account when interpreting the results. Furthermore, due to the small number of dogs from breeds that represented late-onset CED in our study (5 Boxers, 5 Dog de Bordeaux, 3 American Staffordshire Terriers and 2 crossbreed dogs) more research is needed to confirm these findings. The relationship between age and presence of some components of CED has been reported previously [37]; however, data describing specific breeds are limited. In a study by Vermote et al. [37], patients older than 6 years presenting for

Table 5 The frequency (\%) and absolute number of dogs affected with various components of CED depending on weight category

\begin{tabular}{|c|c|c|c|c|c|c|}
\hline \multirow{2}{*}{$\begin{array}{l}\text { Weight } \\
\text { category }\end{array}$} & \multicolumn{6}{|c|}{ Frequency (\%) of CED components } \\
\hline & INC R-U & INC H-U & OCD & MCD & FMCP & UAP \\
\hline Medium & $\begin{array}{l}(37.50) \\
6 / 16\end{array}$ & $\begin{array}{l}(56.25) \\
9 / 16\end{array}$ & $\begin{array}{l}(18.75) \\
3 / 16\end{array}$ & $\begin{array}{l}(31.25) \\
5 / 16\end{array}$ & $\begin{array}{l}(50.00) \\
8 / 16\end{array}$ & $\begin{array}{l}(12.50) \\
2 / 16\end{array}$ \\
\hline Large & $\begin{array}{l}(40.98) \\
50 / 122\end{array}$ & $\begin{array}{l}(73.77) \\
90 / 122\end{array}$ & $\begin{array}{l}(9.02) \\
11 / 122\end{array}$ & $\begin{array}{l}(51.64) \\
63 / 122\end{array}$ & $\begin{array}{l}(54.09) \\
66 / 122\end{array}$ & $\begin{array}{l}(10.65) \\
13 / 122\end{array}$ \\
\hline Extra-large & $\begin{array}{l}(38.71) \\
12 / 31\end{array}$ & $\begin{array}{l}(83.87) \\
26 / 31\end{array}$ & $\begin{array}{l}(19.35) \\
6 / 31\end{array}$ & $\begin{array}{l}(61.29) \\
19 / 31\end{array}$ & $\begin{array}{l}(38.71) \\
12 / 31\end{array}$ & $\begin{array}{l}(12.90) \\
4 / 31\end{array}$ \\
\hline
\end{tabular}

CED canine elbow dysplasia; INC R-U radio-ulnar incongruence; INC $H$ - $U$ humero-ulnar incongruence; FMCP medial coronoid disease with fragmented medial coronoid process; $O C D$ osteochondrosis dissecans within the medial compartment of humeral condyle coronoid process; $M C D$ medial coronoid disease without fragmented medial coronoid process (pathological cartilage and or subchondral bone); UAP ununited anconeal process 


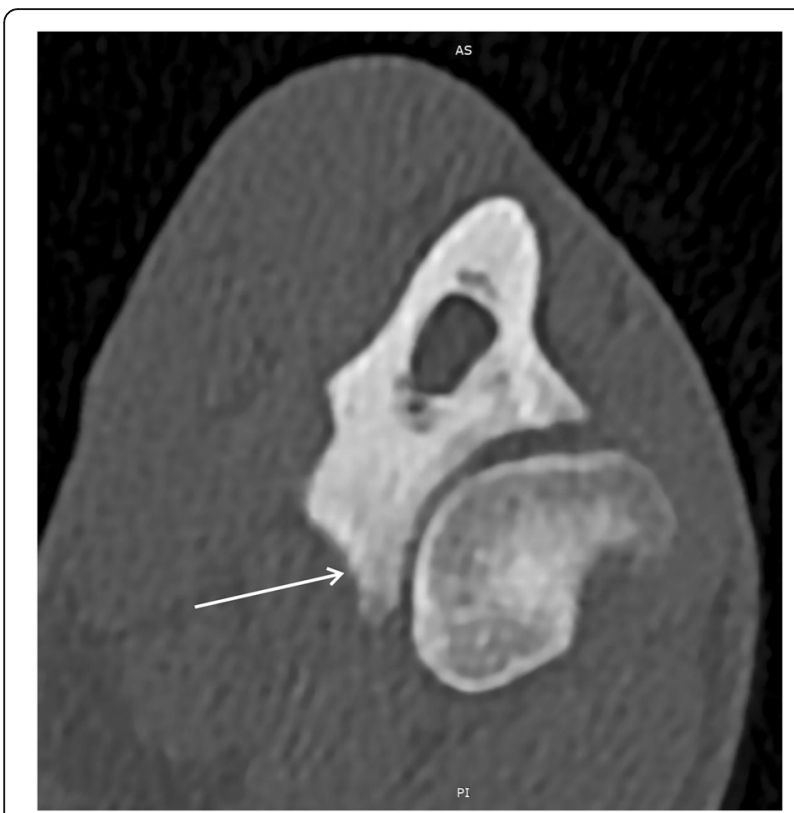

Fig. 12 Frequency of CED-lesions (\%) across tested population of dogs included in the study. INC R-U - radio-ulnar incongruence; INC H-U humero-ulnar incongruence; FMCP - fragmented medial coronoid process; OCD - osteochondrosis dissecans within the medial compartment of humeral condyle coronoid process; MCD - medial coronoid disease without fragmented medial coronoid process (pathological cartilage and or subchondral bone); UAP - ununited anconeal process initial arthroscopic treatment of MCD represented only $12 \%$ of dogs $(77 / 660)$. From dogs older than 6 years included in the mentioned study, 13 out of 16 were Labrador Retrievers, 3 out of 4 were GSDs, 5 out of 6 were Golden Retrievers and 6 out of 8 were mixed-breed dogs. According to O'Neill et al. [26] the median age (in years) at first diagnosis for breeds with over 20 incident was: Labrador Retriever $6.42(2.50-9.08, n=188)$, German Shepherd Dog 5.64 $(0.80-7.77, n=42)$, Staffordshire Bull Terrier $8.02(3.16-10.87, n=32)$, Rottweiler $7.20(1.47-8.17, n=23)$, English Springer Spaniel 7.00 (1.77-12.27, $n=21)$, Golden Retriever 9.75 (5.27-11.65, $n=21)$ and crossbred dogs $7.65(3.39-10.95, n=100)$. However, all dogs with a diagnosis of elbow joint disease made by veterinarians were included in above mentioned study.

\section{Conclusions}

INC H-U, FMCP and MCD were among the most frequently found components of CED (in 129, 92 and 89 dogs, respectively) in the present study. OCD and UAP were the least frequently diagnosed pathologies (in 19 and 16 dogs, respectively). $69.23 \%$ of dogs diagnosed with CED were young ( $\leq 2$ years). Dogs diagnosed with

Table 6 Absolute number of dogs affected with various CED components within breeds

\begin{tabular}{|c|c|c|c|c|c|c|c|c|c|c|c|c|}
\hline \multirow[t]{2}{*}{ Breed } & \multicolumn{6}{|c|}{ Left elbow joint } & \multicolumn{6}{|c|}{ Right elbow joint } \\
\hline & INC R-U & INC H-U & OCD & MCD & FMCP & $\overline{\text { UAP }}$ & INC R-U & INC H-U & OCD & MCD & FMCP & UAP \\
\hline Labrador Retriever & $9 / 43$ & $21 / 43$ & $4 / 43$ & $19 / 43$ & $17 / 43$ & $0 / 43$ & $10 / 43$ & $21 / 43$ & $5 / 43$ & $13 / 43$ & $21 / 43$ & $0 / 43$ \\
\hline German Shepherd Dog & $18 / 40$ & $31 / 40$ & $0 / 40$ & $13 / 40$ & $12 / 40$ & $6 / 40$ & $19 / 40$ & $32 / 40$ & $1 / 40$ & $14 / 35$ & $17 / 40$ & $6 / 40$ \\
\hline Bernese Mountain dog & $8 / 15$ & $13 / 15$ & $1 / 15$ & $5 / 15$ & $8 / 15$ & $2 / 15$ & $9 / 15$ & $13 / 15$ & $1 / 15$ & $5 / 15$ & $10 / 15$ & $1 / 15$ \\
\hline Chow Chow & $3 / 6$ & $6 / 6$ & $2 / 6$ & $0 / 6$ & $6 / 6$ & $0 / 6$ & $2 / 6$ & $6 / 6$ & $2 / 6$ & $0 / 6$ & $6 / 6$ & $0 / 6$ \\
\hline Golden Retriever & $0 / 5$ & $2 / 5$ & $2 / 5$ & $1 / 5$ & $0 / 5$ & $0 / 5$ & $1 / 5$ & $3 / 5$ & $2 / 5$ & $2 / 5$ & $0 / 5$ & $0 / 5$ \\
\hline Boxer & $2 / 5$ & $1 / 5$ & $0 / 5$ & $2 / 5$ & $2 / 5$ & $0 / 5$ & $2 / 5$ & $2 / 5$ & $0 / 5$ & $1 / 5$ & $3 / 5$ & $0 / 5$ \\
\hline Cane Corso & $2 / 5$ & $4 / 5$ & $0 / 5$ & $0 / 5$ & $3 / 5$ & $1 / 5$ & $1 / 5$ & $5 / 5$ & $0 / 5$ & $0 / 5$ & $3 / 5$ & $2 / 5$ \\
\hline Dog de Bordeaux & $0 / 5$ & $3 / 5$ & $2 / 5$ & $2 / 5$ & $2 / 5$ & $0 / 5$ & $0 / 5$ & $4 / 5$ & $2 / 5$ & $3 / 5$ & $1 / 5$ & $0 / 5$ \\
\hline Rottweiler & $1 / 4$ & $3 / 4$ & $1 / 4$ & $2 / 4$ & $1 / 4$ & $0 / 4$ & $1 / 4$ & $4 / 4$ & $1 / 4$ & $4 / 4$ & $0 / 4$ & $0 / 4$ \\
\hline White Swiss Shepherd & $1 / 4$ & $2 / 4$ & $0 / 4$ & $1 / 4$ & $0 / 4$ & $0 / 4$ & $0 / 4$ & $3 / 4$ & $0 / 4$ & $1 / 4$ & $2 / 4$ & $0 / 4$ \\
\hline American Staff. Terrier & $2 / 3$ & $1 / 3$ & $3 / 3$ & $3 / 3$ & $0 / 3$ & $0 / 3$ & $1 / 3$ & $0 / 3$ & $0 / 3$ & $1 / 3$ & $0 / 3$ & $0 / 3$ \\
\hline Bouvier des Flandres & $2 / 3$ & $3 / 3$ & $1 / 3$ & $1 / 3$ & $2 / 3$ & $0 / 3$ & $1 / 3$ & $2 / 3$ & $2 / 3$ & $2 / 3$ & $1 / 3$ & $0 / 3$ \\
\hline Polish Tatra Sheepdog & $1 / 3$ & $2 / 3$ & $1 / 3$ & $0 / 3$ & $2 / 3$ & $0 / 3$ & $1 / 3$ & $2 / 3$ & $0 / 3$ & $1 / 3$ & $1 / 3$ & $0 / 3$ \\
\hline English Bulldog & $1 / 3$ & $0 / 3$ & $0 / 3$ & $1 / 3$ & $0 / 3$ & $0 / 3$ & $0 / 3$ & $0 / 3$ & $0 / 3$ & $1 / 3$ & $2 / 3$ & $0 / 3$ \\
\hline Eurasian Shepherd & $0 / 2$ & $1 / 2$ & $0 / 2$ & $1 / 2$ & $0 / 2$ & $0 / 2$ & $1 / 2$ & $2 / 2$ & $0 / 2$ & $1 / 2$ & $0 / 2$ & $1 / 2$ \\
\hline Mix-breed & $0 / 2$ & $1 / 2$ & $0 / 2$ & $1 / 2$ & $1 / 2$ & $0 / 2$ & $1 / 2$ & $2 / 2$ & $0 / 2$ & $1 / 2$ & $1 / 2$ & $1 / 2$ \\
\hline Caucasian Shepherd & $0 / 2$ & $2 / 2$ & $0 / 2$ & $0 / 2$ & $1 / 2$ & $1 / 2$ & $0 / 2$ & $2 / 2$ & $0 / 2$ & $2 / 2$ & $0 / 2$ & $1 / 2$ \\
\hline Newfoundland & $2 / 2$ & $2 / 2$ & $1 / 2$ & $1 / 2$ & $1 / 2$ & $0 / 2$ & $2 / 2$ & $2 / 2$ & $1 / 2$ & $1 / 2$ & $1 / 2$ & $0 / 2$ \\
\hline Argentinian Mastiff & $1 / 2$ & $2 / 2$ & $0 / 2$ & $2 / 2$ & $0 / 2$ & $0 / 2$ & $1 / 2$ & $2 / 2$ & $0 / 2$ & $2 / 2$ & $0 / 2$ & $0 / 2$ \\
\hline Pitbull & $0 / 2$ & $0 / 2$ & $0 / 2$ & $0 / 2$ & $0 / 2$ & $0 / 2$ & $0 / 2$ & $0 / 2$ & $0 / 2$ & $1 / 2$ & $0 / 2$ & $0 / 2$ \\
\hline
\end{tabular}

CED canine elbow dysplasia; INC $R-U$ radio-ulnar incongruence; INC $\mathrm{H}-U$ humero-ulnar incongruence; FMCP medial coronoid disease with fragmented medial coronoid process; $O C D$ osteochondrosis dissecans within the medial compartment of humeral condyle coronoid process; $M C D$ medial coronoid disease without fragmented medial coronoid process (pathological cartilage and or subchondral bone); UAP ununited anconeal process; 0 - no lesion 
Table 7 Types of CED lesions in single-digit breed representants

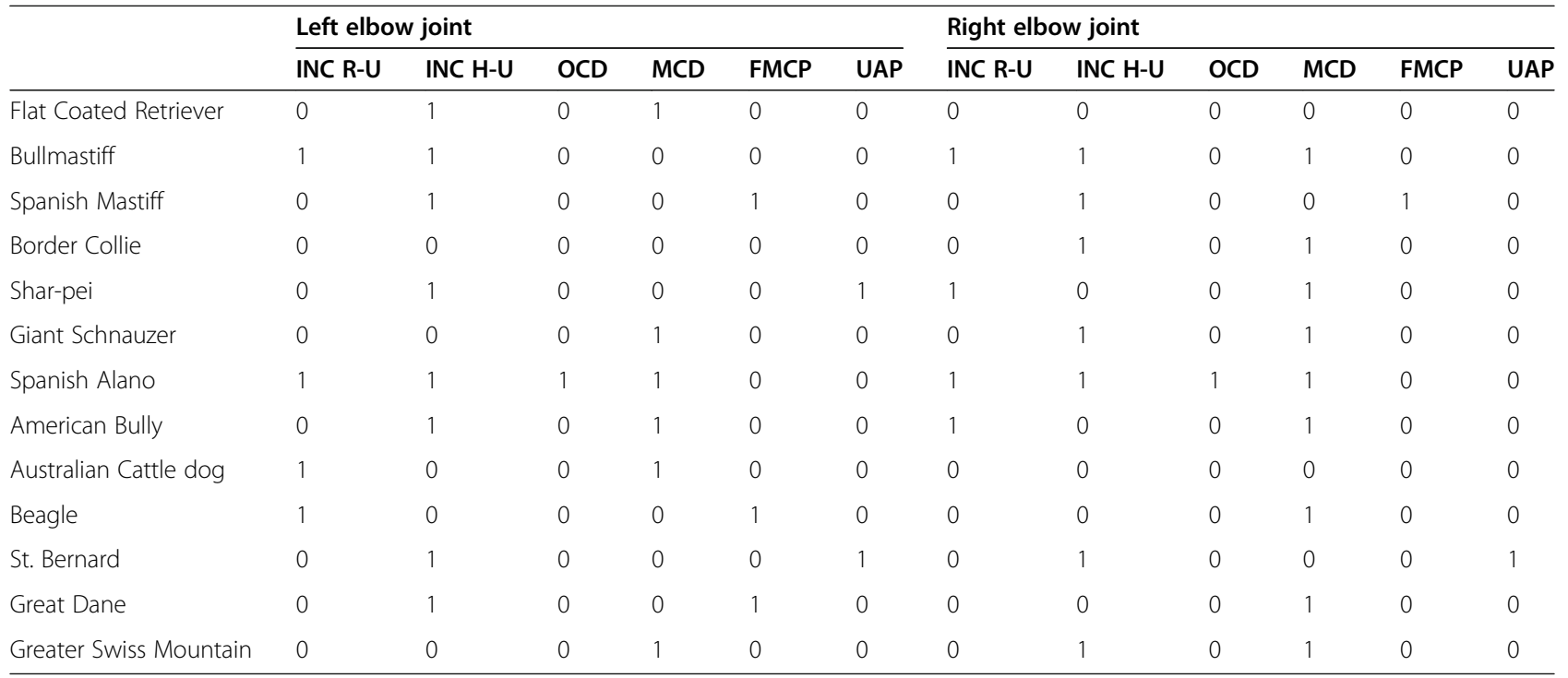

CED canine elbow dysplasia; INC R-U radio-ulnar incongruence; INC H-U humero-ulnar incongruence; FMCP medial coronoid disease with fragmented medial coronoid process; $O C D$ osteochondrosis dissecans within the medial compartment of humeral condyle coronoid process; $M C D$ medial coronoid disease without fragmented medial coronoid process (pathological cartilage and or subchondral bone); UAP ununited anconeal process; " 1 "lesion confirmed; "0 "- no lesion

INC R-U were significantly younger than dogs without this component of CED. A similar result was observed for INC H-U. Boxers, Dog de Bordeaux, American Staffordshire terriers and mixed-breed dogs were diagnosed later in life than the other breeds. OA of varying severity was found in $72.18 \%$ of dogs. Males accounted for more than $75 \%$ of the study population.

\section{Abbreviations \\ 3D MPR: 3D Multiplanar reconstruction; CED: Canine elbow dysplasia; CT: Computed tomography; FMCP: Fragmented medial coronoid process (as a medial coronoid disease with fragmented medial coronoid process); IEWG: International elbow work group guidelines; INC H-U: Humero-ulnar incongruence; INC R-U: Radio-ulnar incongruence; MCD: Medial coronoid disease (without fragmented medial coronoid process); PANOS: Panosteitis; OA: Osteoarthritis; OC: Osteochondrosis; OCD: Osteochondrosis dissecans; UAP: Ununited anconeal process}

\section{Acknowledgements}

We thank Wiktoria Mól and Emma Evans for English language editing.

\section{Authors' contributions}

$\mathrm{MH}$ - participated in designing and coordination of the study, performed clinical examination, blood tests, computed tomography scans, collected the data, writing - original draft, writing - review \& editing; WKP - participated in designing, coordination of the study and drafting the manuscript, writing - review \& editing; JJR - participated in designing and coordination of the study, did research on available knowledge about the topic, writing original draft, writing - review \& editing; MN - performed statistical analysis, writing - review \& editing, DN - collected the data, writing - review \& editing; KCP - performed statistical analysis, writing - review \& editing; AMN participated in designing, coordination of the study, writing - review \& editing; MK - participated in the data collection, writing - original draft, MPM - analysis and interpretation of data, statistical analysis, writing - review \& editing, critical revision. All authors read and approved the final manuscript.

\section{Funding}

This work was supported partially by the statutory funding No. 506.514.05.00 of the Faculty of Veterinary Medicine and Animal Science Poznan University of Life Sciences, Poland; Department of Preclinical Sciences and Infectious
Diseases and by the Ministry of Science and Higher Education program "Regional Initiative Excellence" in years 2019-2022, Project No. 005/RID/2018/ 19. The funding body did not have any role in the design, analysis or writing of this study.

\section{Availability of data and materials}

The data used to support the findings of this study are available from the corresponding author upon reasonable request.

\section{Declarations}

Ethics approval and consent to participate

According to the Act on the Protection of Animals Used for Scientific or Educational Purposes in Poland adopted on 15th January 2015 and according to earlier regulations the study described in this manuscript did not require permission of the Local Ethical Commission for Investigations on Animals. Written informed consent to participate was obtained from the owners of the patients.

\section{Consent for publication}

Written informed consent for publication of their clinical details and images was obtained from all the owners of the patients.

\section{Competing interests}

The authors declare that there is no conflict of interest regarding the publication of this paper.

\section{Author details}

'Department of Internal Diseases and Diagnostics, Poznan University of Life Sciences, ul. Wołyńska 35, 60-637 Poznań, Poland. ${ }^{2}$ Department of Clinical Sciences, College of Veterinary Medicine, North Carolina State University, Raleigh, North Carolina 27607, USA. ${ }^{3}$ Department of Animal Anatomy, Poznan University of Life Sciences, ul. Wojska Polskiego 71C, 60-625 Poznań, Poland. ${ }^{4}$ University Centre for Veterinary Medicine, Szydłowska 43, 60-656 Poznan, Poland. ${ }^{5}$ Small Animal Veterinary Clinic, Klinika Psa i Kota, ul. Bolesława Krzywoustego 105/21, 51-166 Wrocław, Poland. ${ }^{6}$ Department of Neurological Surgery, Feinberg School of Med, 676 N St. Clair, Suite 2210, Chicago, IL 60611, USA. Department of Small Animal Surgery, Medvet Chicago, 3123 N. Clybourn Ave, Chicago, IL 60618, USA. ${ }^{8}$ Department of Preclinical Sciences and Infectious Diseases, Poznan University of Life Sciences, ul. Wołyńska 35, 60-637 Poznań, Poland. 
Received: 9 October 2020 Accepted: 19 August 2021

\section{Published online: 06 September 2021}

\section{References}

1. Baers G, Keller GG, Famula TR, Oberbauer AM. Heritability of unilateral elbow dysplasia in the dog: a retrospective study of sire and dam influence. Front Vet Sci. 2019;6:422. https://doi.org/10.3389/fvets.2019.00422.

2. Narojek T, Fiszdoni K, Hanysz E. Canine elbow dysplasia in different breeds. Bull Vet Inst Pulawy. 2008;52:169-73.

3. Sjostrom L. Ununited anconeal process in the dog. Vet Clin North Am Exot Anim Pract. 1998;28(1):75-86. https://doi.org/10.1016/S0195-5616(98)50005-8.

4. Hazewinkel HAW, Meij BP, Nap RC, Dijkshoorn NE, Ubbink G, Wolvekamp W. Radiographic views for elbow dysplasia screening in Bernese Mountian Dogs. In: Proceedings of the 7th International Elbow Working Group Meeting, Constance, Germany; 1995;pp.29-32.

5. Mostafa AA, Nolte I, Wefstaedt P. The prevalence of medial coronoid process disease is high in lame large breed dogs and quantitative radiographic assessments contribute to the diagnosis. Vet Radiol Ultrasound. 2018;59(5):516-28. https://doi.org/10.1111/vru.12632.

6. Morgan J, Wind A, Davidson A. Bone dysplasias in the labrador retriever: a radiographic study. J Am Anim Hosp Assoc. 1999;35(4):332-40. https://doi. org/10.5326/15473317-35-4-332.

7. Morgan J, Wind A, Davidson AP. Elbow Dysplasia. In: Hereditary Bone and Joint Diseases in the Dog. First ed. Germany: Hannover Schultersche; 2000. p. 41.

8. Coopman F, Verhoeven G, Saunders J, Duchateau L, van Bree H. Prevalence of hip dysplasia, elbow dysplasia and humeral head osteochondrosis in dog breeds in Belgium. Vet Rec. 2008;163(22):654-8. https://doi.org/10.1136/vr.1 63.22.654.

9. Lavrijsen ICM, Heuven HCM, Meij BP, et al. Prevalence and co-occurrence of hip dysplasia and elbow dysplasia in Dutch pure-bred dogs. Prev Vet Med. 2014;114:11.

10. Hornof WJ, Wind AP, Wallack ST, et al. Canine elbow dysplasia. The early radiographic detection of fragmentation of the coronoid process. Vet Clin North Am Small Anim Pract. 2000;30:257-66.

11. Reichle JK, Park RD, Bahr AM. Computed tomographic findings of dogs with cubital joint lameness. Vet Radiol Ultrasound. 2000;41(2):125-30. https://doi. org/10.1111/j.1740-8261.2000.tb01465.x.

12. Cook CR, Cook JL. Diagnostic imaging of canine elbow dysplasia: a review. Vet Surg. 2009;38(2):144-53. https://doi.org/10.1111/j.1532-950X.2008.00481.x.

13. Tobias TA, Miyabayashi T, Olmstead ML, Hendrick LA. Surgical removal of fragmented medial coronoid process in the dog: comparative effects of surgical approach and age at time of surgery. J Am Anim Hosp Assoc. 1994; 30:360-8.

14. Kunst CM, Pease AP, Nelson NC, Habing G, Ballegeer EA. Computed tomographic identification of dysplasia and progression of osteoarthritis in dog elbows previously assigned OFA grades 0 and 1. Vet Radiol Ultrasound. 2014;55(5):511-20. https://doi.org/10.1111/vru.12171.

15. Mostafa A, Nolte I, Wefstaedt P. Quantitative radiographic evaluation of elbow incongruity in labrador and golden retrievers with confirmed medial coronoid disease. Vet Comp Orthop Traumatol. 2019;32(01):010-7. https:// doi.org/10.1055/s-0038-1672210.

16. Lappalainen AK, Molsa S, Liman A, Laitinen-Vapaavuori O, Snellman M. Radiographic and computed tomography findings in Belgian shepherd dogs with mild elbow dysplasia. Vet Radiol Ultrasound. 2009;50(4):364-9. https://doi.org/10.1111/j.1740-8261.2009.01551.x.

17. Moores AP, Benigni L, Lamb CR. Computed tomography versus arthroscopy for detection of canine elbow dysplasia lesions. Vet Surg. 2008;37(4):390-8. https://doi.org/10.1111/j.1532-950X.2008.00393.x.

18. Van Bree H, Van Ryssen B. Imaging the canine elbow: radiography, computed tomography and arthroscopy. Vet Annu. 1995;35:118-29.

19. Lau SF, Wolschrijn CF, Hazewinkel HAW, Siebelt M, Voorhout G. The early development of medial coronoid disease in growing Labrador retrievers: radiographic, computed tomographic, necropsy and micro-computed tomographic findings. Vet J. 2013;197(3):724-30. https://doi.org/10.1016/j. tvjl.2013.04.002.

20. Griffon DJ, Mostafa AA, Blond L, et al. Radiographic, computed tomographic, and arthroscopic diagnosis of radioulnar incongruence in dogs with medial coronoid disease. Vet Surg. 2018;47(3):33-342.

21. Hou Y, Wang Y, Lu X, et al. Monitoring hip and elbow dysplasia achieved modest genetic improvement of 74 dog breeds over 40 years in USA. PLoS One. 2013;8:e7639.
22. Lewis TW, Ilska JJ, Blott SC, Woolliams JA. Genetic evaluation of elbow scores and the relationship with hip scores in UK Labrador retrievers. Vet J. 2011;189(2):227-33. https://doi.org/10.1016/j.tvjl.2011.06.024.

23. Everts RE (2000). Molecular Genetic Studies in the Dog; Application to Fragmented Coronoid Process (FCP) in the Labrador Retriever. PhD Thesis, University of Utrecht.

24. International Elbow Working Group. Guidelines for radiographic examination and interpretation of the elbow joint. Proceedings of the 26th annual meeting of the IEBW Group, Amsterdam, Holland, 2011.

25. Kramer A, Holsworth IG, Wisner ER, et al. Computed tomographic evaluation of canine radioulnar incongruence in vivo. Vet Surg. 2006;35(1):24-9. https:// doi.org/10.1111/j.1532-950X.2005.00107.x.

26. O'Neill DG, Brodbelt DC, Hodge R, et al. Epidemiology and clinical management of elbow joint disease in dogs under primary veterinary care in the UK. Canine Med Genet. 2020;7(1):15.

27. Proks P, Necas A, Stehlik L, Srnec R, Griffon DJ. Quantification of Humeroulnar incongruity in $L$ abrador $R$ etrievers with and without medial coronoid disease. Vet Surg. 2011;40(8):981-6. https://doi.org/10.1111/j.1532950X.2011.00907.x

28. Snášil R, Proks P, Nečasová A, Michalčáková K, Nečas A. Měření humeroulnární inkongruity loketního kloubu u psů pomocí výpočetní tomografie [Canine Elbow Humeroulnar Incongruity Measurements Using Computed Tomography]. Acta Chir Orthop Traumatol Cechoslov. 2017;84(4): 299-303.

29. Skinner OT, Warren-Smith CMR, Burton NJ, Parsons KJ. Computed tomographic evaluation of elbow congruity during arthroscopy in a canine cadaveric model. Vet Comp Orthop Traumatol. 2014;28(1):19-24. https://doi. org/10.3415/NCOT-14-02-0017.

30. Demko J, McLaughlin R. Developmental orthopedic disease. Vet Clin North Am Small Anim Pract. 2005;35(5):1111-35. https://doi.org/10.1016/j.cvsm.2 005.05.002.

31. Anderson $\mathrm{KL}, \mathrm{O}^{\prime}$ Neill DG, Brodbelt DC, Church DB, Meeson RL, Sargan D, et al. Prevalence, duration and risk factors for appendicular osteoarthritis in a UK dog population under primary veterinary care. Sci Rep. 2018;8(1):5641. https://doi.org/10.1038/s41598-018-23940-z.

32. Huck JL, Biery DN, Lawler DF, et al. A longitudinal study of the influence of lifetime food restriction on development of osteoarthritis in the canine elbow. Vet Surg. 2009;38(2):192-8. https://doi.org/10.1111/j.1532-950X.2008. 00487.x.

33. Eljack $H$, Werner $H$, Böttcher P. Sensitivity and specificity of $3 D$ models of the radioulnar joint cup in combination with a sphere fitted to the ulnar trochlear notch for estimation of radioulnar incongruence in vitro. Vet Surg. 2013;42(4):365-70. https://doi.org/10.1111/j.1532-950X.2013.01096.x.

34. Grøndalen J, Grøndalen T. Arthrosis in the elbow joint of young rapidly growing dogs. V. a pathoanatomical investigation. Nord Vet Med. 1981;33:1-16.

35. Carpenter LG, Schwarz PD, Lowry JE, Park RD, Steyn PF. Comparison of radiologic imaging techniques for diagnosis of fragmented medial coronoid process of the cubital joint in dogs. J Am Vet Med Assoc. 1993;203(1):78-83.

36. Meyer-Lindenberg A, Fehr M, Nolte I. Co-existence of ununited anconeal process and fragmented medial coronoid process of the ulna in the dog. J Small Anim Pract. 2006;47(2):61-5. https://doi.org/10.1111/j.1748-5827.2006. 00051.x.

37. Vermote KA, Bergenhuyzen AL, Gielen I, van Bree H, Duchateau L, van Ryssen B. Elbow lameness in dogs of six years and older: arthroscopic and imaging findings of medial coronoid disease in 51 dogs. Vet Comp Orthop Traumatol. 2010;23(1):43-50. https://doi.org/10.3415/VCOT-09-03-0032.

\section{Publisher's Note}

Springer Nature remains neutral with regard to jurisdictional claims in published maps and institutional affiliations. 